\title{
Cumulative, Collaborative, Disruptive Architectural Geometry in Research, Practice, and its Imminent Mainstream Future Vishu Bhooshan ${ }^{1,2}$, Shajay Bhooshan ${ }^{1,3}$
}

${ }^{1}$ Zaha Hadid Computation \& Design Research Group (ZHCODE), Zaha Hadid Architects, London.

${ }^{2}$ Architectural Computation, Bartlett School of Architecture, University College of London (UCL), London.

${ }^{3}$ Block Research Group, Institute of Technology in Architecture, ETH, Zurich.

1vishu.bhooshan@zaha-hadid.com

${ }^{2}$ shajay.bhooshan@zaha-hadid.com
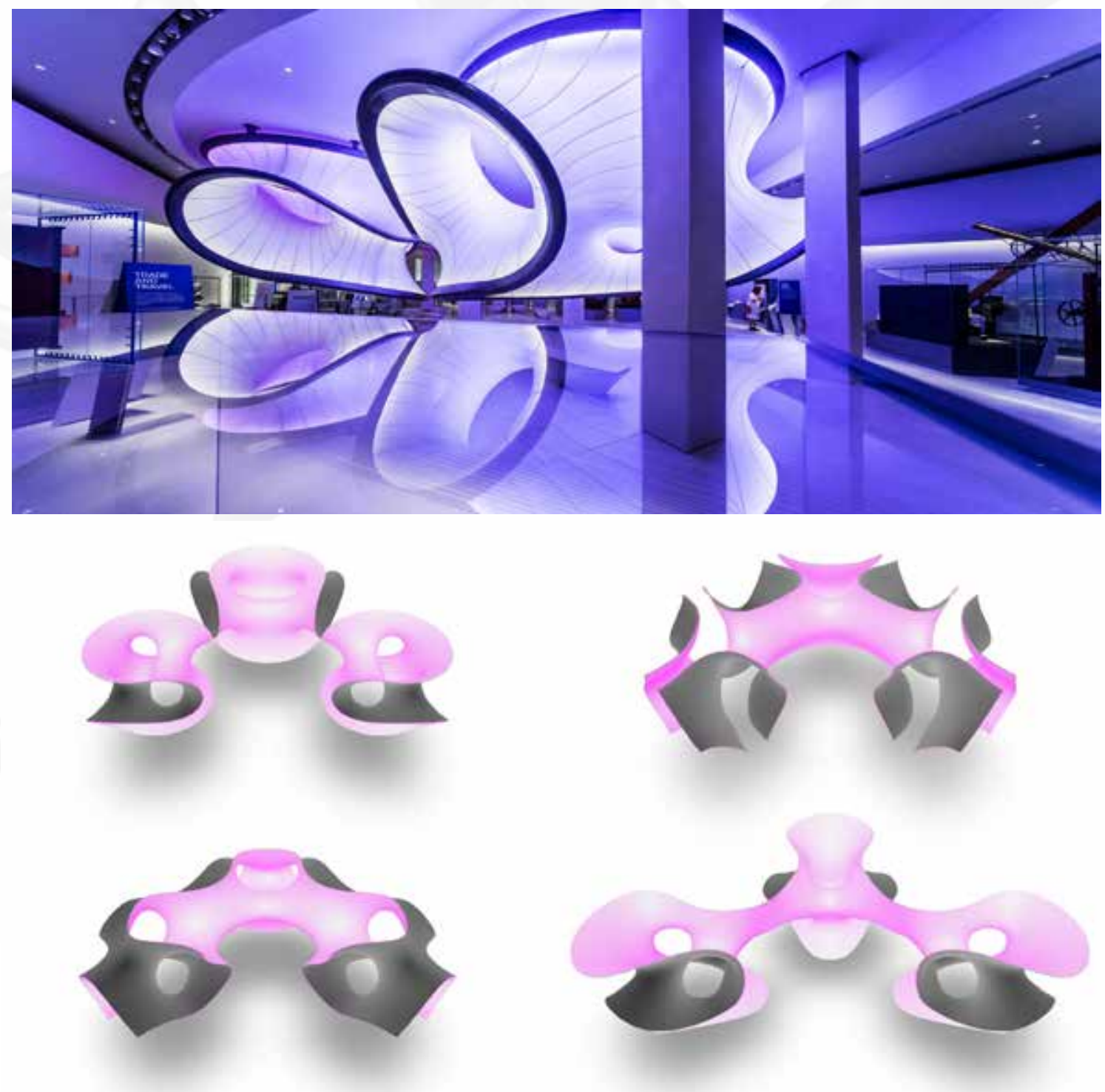

Figure 01: Realized design (Top) \& various possible shapes of minimal surface for the central fabric pod (Below). Mathematics: The Winton Gallery, Science Museum, London (Zaha Hadid Architects). Photograph (Top) (c) Matt Danby. 

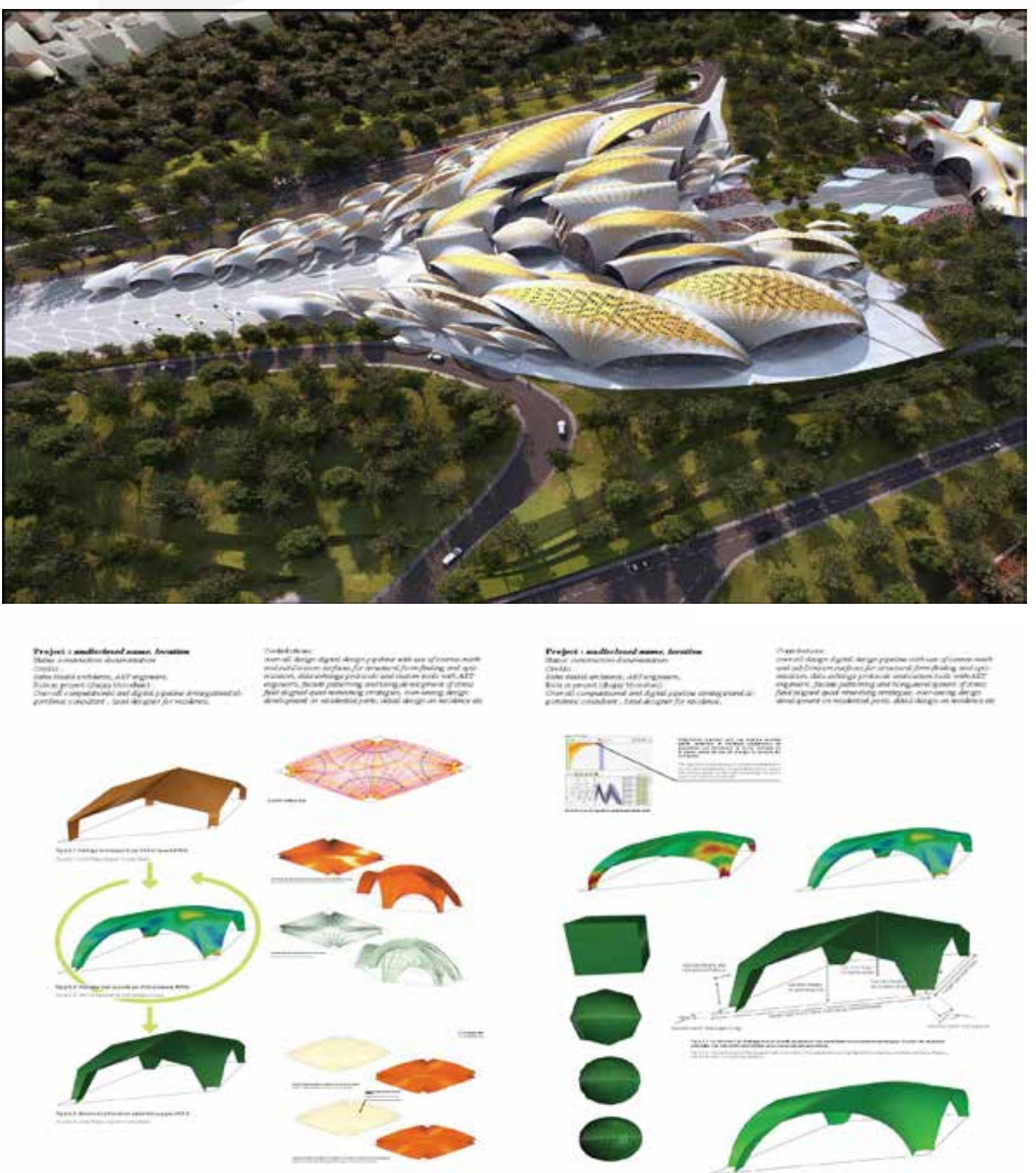

Figure 02: Collaborative workflow with the principal stakeholders of the architectural design process. Undisclosed Project (Zaha Hadid Architects with AKT II).

Solutions to the significant social, ecological and economic opportunities and problems of 21st century architecture and urbanism involve a vast number of variables. These solutions will require the use of data-driven technologies to acquire physical and social information of sites and consumer communities, digital technologies to design for the briefs so acquired and robotic manufacturing to deliver the designed solutions effectively.

In this context, Architectural Geometry ${ }^{1}$ (AG) is a highly relevant design technology paradigm. AG focusses on the synthesis of shapes that guarantee structural and fabrication optimality. It is also closely aligned with and complementary to the development of robotic and digital fabrication (RDF). 
Further, in combining historical geometry-based methods of structural analysis, modern mathematics as used in computer graphics (CG) and computational technologies, the field is opening up several rich shape-possibilities that are also economically viable (Fig. 1).
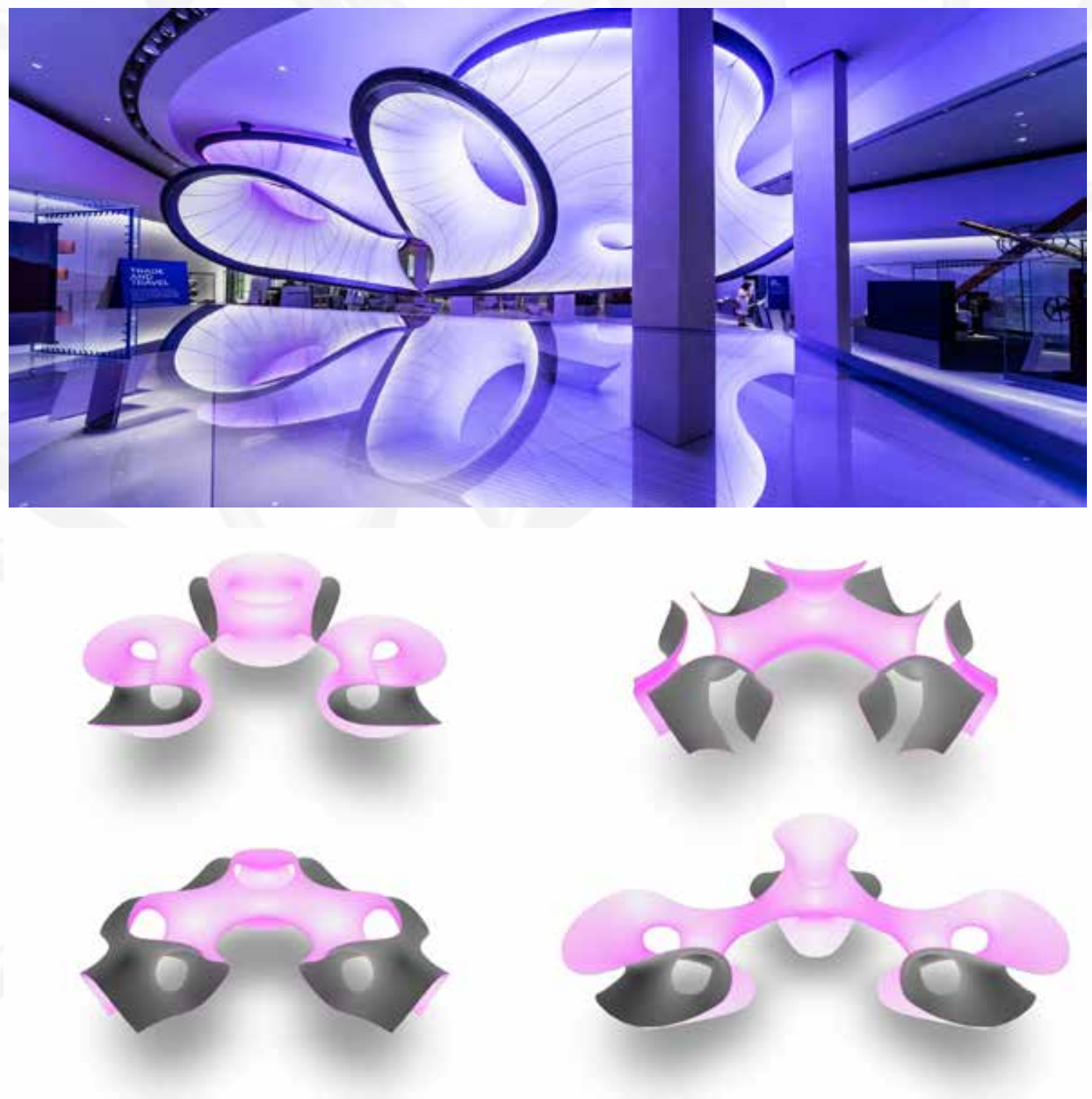

Design that is so digitally empowered is proving to be significantly more effective in terms of spatial expressivity and user experience ${ }^{2}$, ecologically ${ }^{3}$, preservation of building trades ${ }^{4}$ etc. Thus, the recent and increasing popularity of AG is not surprising, considering it has brought the principal stakeholders in the architectural design process - architects, engineers \& fabricators, and their respective toolchains much closer together ${ }^{5,6}$ (Fig. 2).

AG, despite its design benefits noted above, is currently expensive to make digitally as the creation of such geometries involves acquisition of considerable digital skills, development of toolsets that are either non-existent or unavailable within commercial design environments, creation of physical exemplars ${ }^{5-11}$ etc. It is also expensive to make physically as the $20^{\text {th }}$ century, automation-centric production systems are misaligned with structurally efficient, material conserving shapes of AG. AG is thus currently reliant on $\mathrm{RDF}$ and other early-stage technologies and methodologies for its physical realization ${ }^{12,6}$ etc. (Fig. 3, 4). 

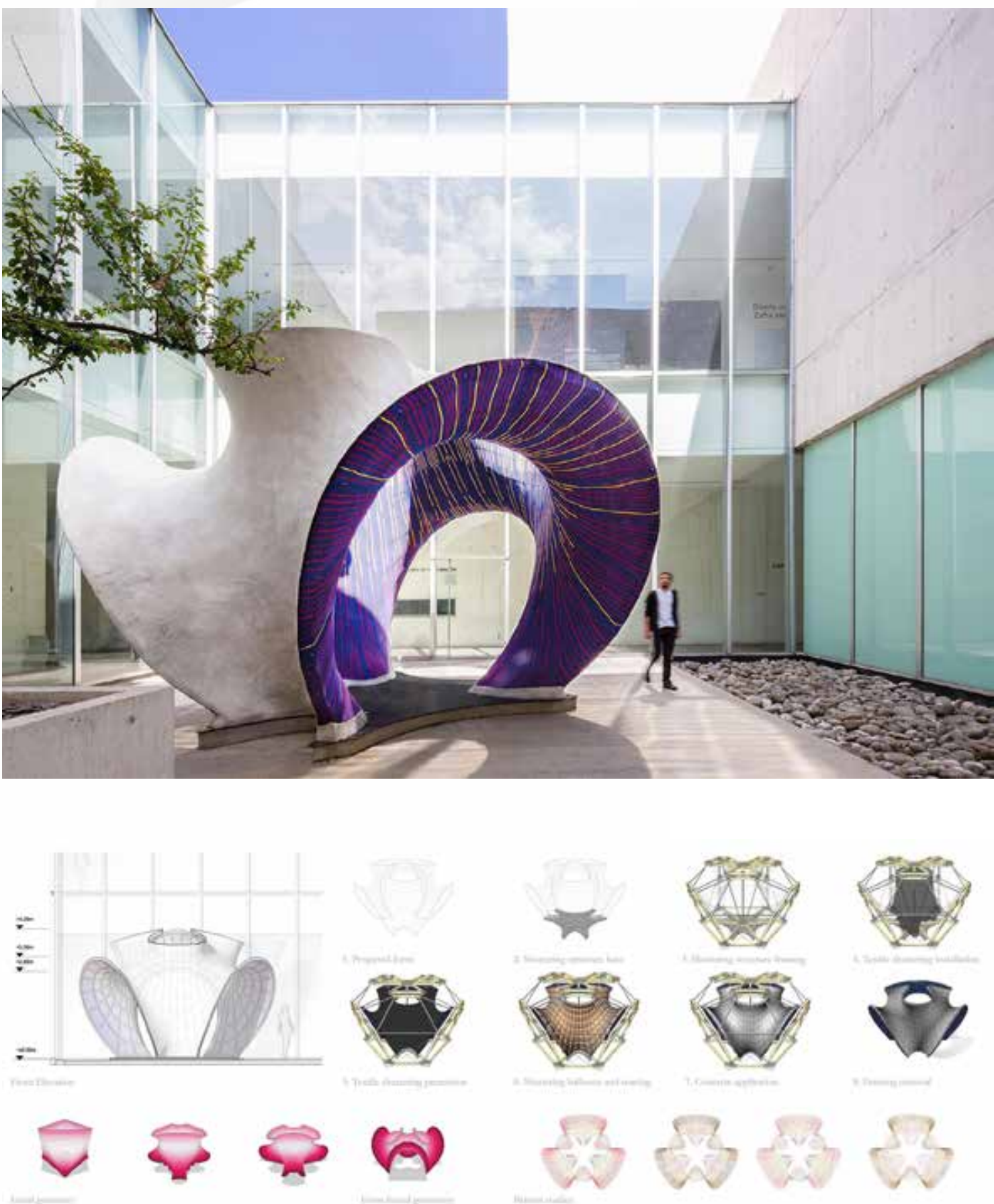

Figure 03: Prototyping of knitted fabric formwork with cast in-situ concrete shell (Top), Construction sequence, computational form finding and pattern generation studies (Bottom). Knit Candela, Mexico City (Block Research Group \& Zaha Hadid Architects with Architecture Extrapolated). Photograph (Top) (c) Angelica Ibarra. 


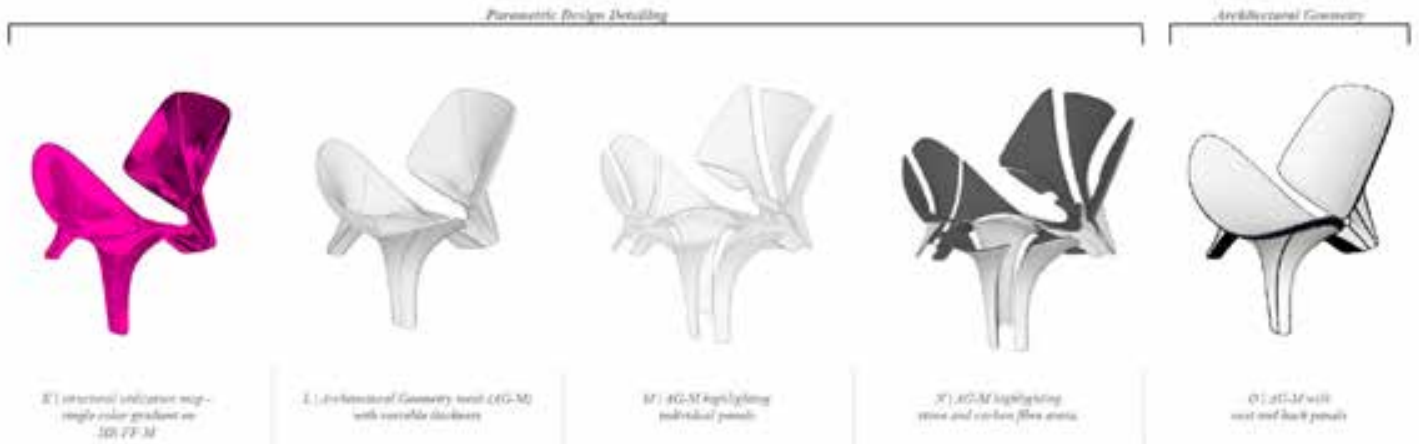

Figure 04: Prototyping of fiber reinforced stone chair (Top) and development of custom integrated tool chain (Below). Undisclosed Project (Zaha Hadid Architects \& AKT II with New Fundamental Research Group \& Generelli SA). Photograph (Top) (c) Generelli SA.

Efforts to overcome these critical cost obstacles are focused along two dominant vectors:

\section{- Improving creation and manufacture of AG designs:}

The discipline of AG is consolidating the research and demonstration gains from its first decade of existence, and progressing towards full scale and mainstream architectural applications with ongoing efforts at the research epi $\square$ centers in Stuttgart, Zurich and elsewhere ${ }^{13-15}$. The maturation of several start $\square$ up businesses in $\mathrm{RDF}^{16-18}$ along with the encoding of expertise in reusable code assets ${ }^{19-21}$ for ease of creation and manipulation of $\mathrm{AG}$, further reinforces this trend.
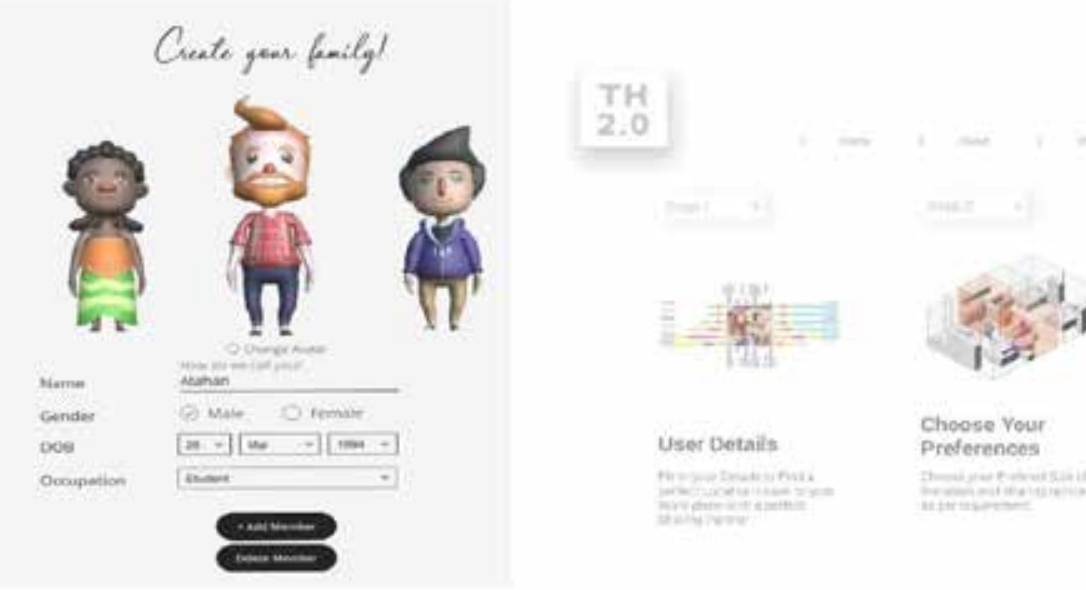

User Details

Choose Vour Preferenoes

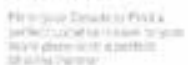

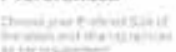

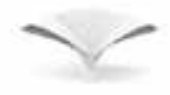

Explore your Space

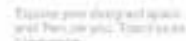



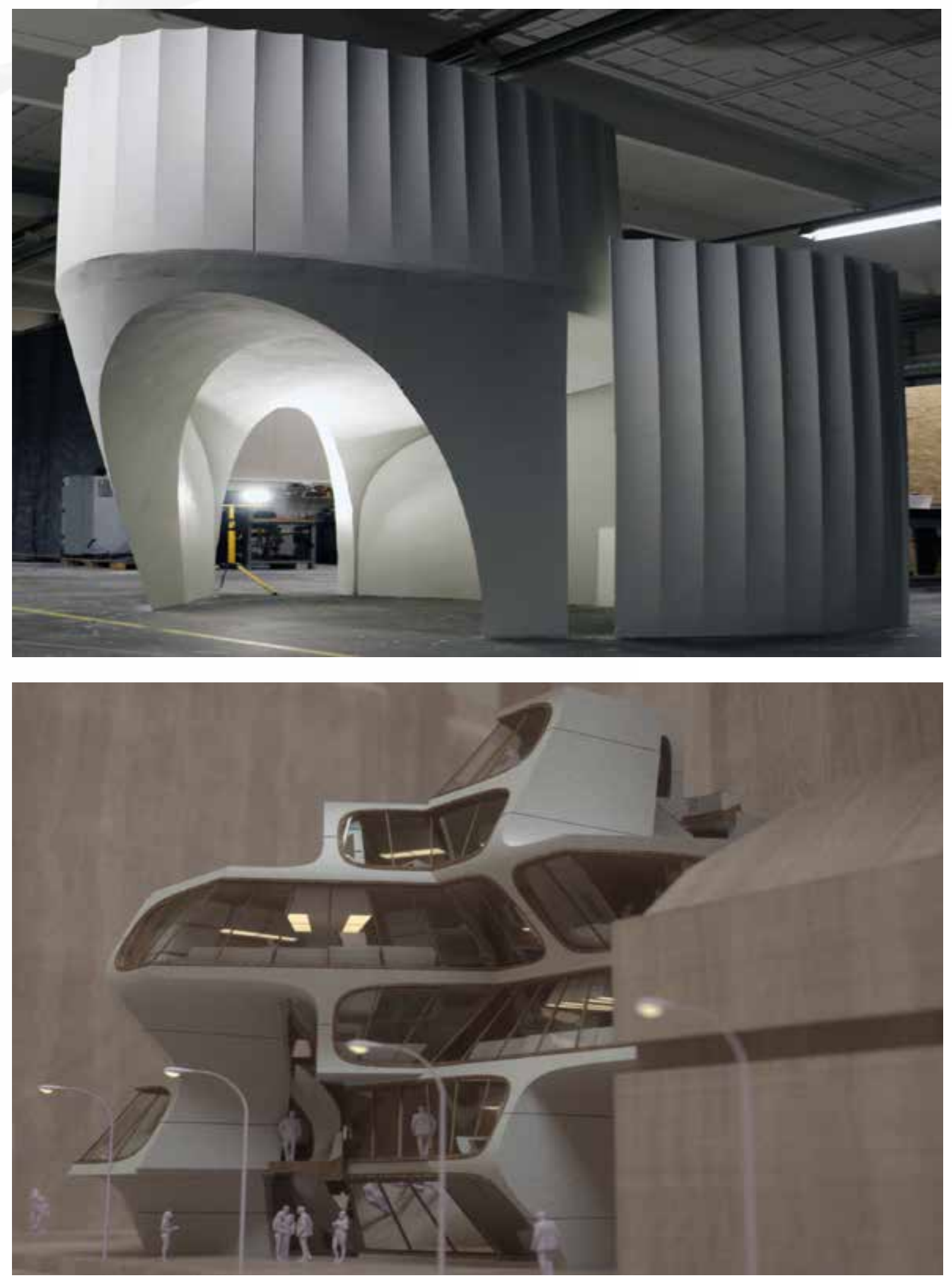

Figure 06: One of the outcomes from a particular instance of game-play was physically realized using the commercialized technology of Robotic Hot Wire cutting offered by Odico Robotic Formworks. This technology is now available as a 'factory-in-a-box' that can be shipped to various locations. The foam being lightweight also provides logistical advantages, apart from insulation properties. (Top) Computer generated view of an outcome from a particular instance of game-play, showing the variety of unit sizes and formal expressions, which nonetheless exhibit efficiencies 
in manufacturing due to digitized manufacture and assembly (Bottom). Game Play \& Housing Configurator (Nahmad Bhooshan Studio, Architectural Association Design Research Lab (AADRL)).

AG, which is congenial with Tectonism ${ }^{2,23,15}$, has proven to be a highly effective technology-led design paradigm for the 21st century incorporating essential aspects of structure and fabrication in addition to increasingly encoding the social, ecological and economic parameters into the shape modeling process. The immediate outlook for AG is to significantly improve its prospects of mainstream impact - reducing the costs associated with its digital creation by in turn capturing and encoding the significant tacit know-how that is currently part of the creation process and thus its cost. Such a synergy already underway in the graphics community - Geometric deep learning ${ }^{24}$ - would help further open the solution space and its exploration, whilst addressing the cost of digitally creating AG with potential machine assisted creation of AG, machine $\square$ assisted tutoring of novice designers, institutional preservation or encoding of tacit know $\square$ how etc. These, along with the rapid evolution of RDF technologies, would provide a sound basis for disruptive, industry-wide applications.

\section{References}

Pottmann, H. (2010). Architectural geometry as design knowledge. Architectural Design, 80, 72-77.

Schumacher, P. (2014). The congeniality of architecture and engineering. Shell Struct. Archit. Form Find. Optim. 271.

Rippmann, M., Liew, A., Van Mele, T., \& Block, P. (2018). Design, fabrication and testing of discrete 3D sand $\square$ printed floor prototypes. Mater. Today Commun, 15, 254-259.

Fallacara, G. (2009). Toward a stereotomic design: Experimental constructions and didactic experiences. In Proceedings of the Third International Congress on Construction History 553.

Louth, H., Reeves, D., Koren, B., Bhooshan, S., \& Schumacher, P. (2017). A prefabricated dining pavilion: Using structural skeletons, developable offset meshes, kerf-cut and bent sheet materials. In: Menges, A., Sheil, B., Glynn, R., \& Skavara M (eds) Fabricate 2017. UCL Press, pp 58-67.

Bhooshan, V., Louth, H. D., Bhooshan, S., \& Schumacher, P. (2018). Design workflow for additive manufacturing: a comparative study. International Journal of Rapid Manufacturing 7(2-3): 240-276.

Bhooshan, S., \& El Sayed, M. (2012). Subdivision surfaces in architectural form finding and fabric forming. 2nd International Conference on Flexible Formwork (ICFF). The International Society of Fabric Formwork, Bath.

Bhooshan, S. et al. (2015). Applying dynamic relaxation techniques to form-find and manufacture curve-crease folded panels. Simulation, Vol. 91, No. 9, pp.773-786.

Bhooshan, S. et al. (2015). Curve-folded form-work for cast, compressive skeletons. In Proceedings of the Symposium on Simulation for Architecture and Urban Design, SimAUD '15. Society for Computer Simulation International, San Diego, CA, USA, pp. 221-228.

Bhooshan, V., Reeves, D., Bhooshan, S., \& Block, P. (2018) Maya Vault—a mesh modelling environment for discrete funicular structure. Nexus Network Journal, 20(3): 567-582.

Bhooshan, V., Louth, H., Bieling, L., \& Bhooshan, S. (2020). Spatial Developable Meshes. In: Gengnagel C., Baverel O., Burry J., Ramsgaard Thomsen M., Weinzierl S. (eds) Impact: Design With All Senses. DMSB 2019. Springer, Cham.

Mcgee, W., Feringa, J., \& Søndergaard, A. (2013). Processes for an architecture of volume, Rob $\mid$ Arch 2012. Springer, pp.62-71.

IntCDC. Cluster of Excellence Integrative Computational Design and Construction for Architecture. (2019). 
NCCR_dFab. National Centre of Competence in Research (NCCR) Digital Fabrication. (2017).

Block, P. et al. (2020). Redefining structural art: strategies, necessities and opportunities. The Structural Engineer, 98(1), pp.66-72.

Odico robotic technologies. (2012). Retrieved from https://www.odico.dk/en/technologies. Accessed on $2^{\text {nd }}$ March 2020.

AIBuild. (2015). AIBuild. Retrieved from https://ai-build.com/. Accessed on $2^{\text {nd }}$ March 2020).

BranchTechnology. (2015). Branch Technology. Retrieved from https://www.branch.technology/. Accessed on $2^{\text {nd }}$ March 2020.

Van Mele T. et al. (2017). Compas: A framework for computational research in architecture and structures. Retrieved from http://compas-dev.github.io/. Accessed on 2nd March 2020.

Jacobson, A., Panozzo, D., \& others. (2018). LibIGL: A Simple C++ geometry processing library. Retrieved from https://libigl.github.io/. Accessed on $2^{\text {nd }}$ March 2020.

Bhooshan, V., Bhooshan, S., \& others. (2019). ZSpace: A Simple C++ collection of geometry data-structures and algorithms. Retrieved from https://github.com/venumb/ZSPACE. Accessed on $2^{\text {nd }}$ March 2020.

Hypar. (2019). Hypar Explore, Available at https://hypar.io/. (Accessed: 2nd March 2020).

Schumacher, P. (2017). Tectonism in Architecture, Design and Fashion - Innovations in Digital Fabrication as Stylistic Drivers. In AD 3D-Printed Body Architecture, guest-edited by Leach, N. \& Farahi, B., Architectural Design, Profile No. 250, November/December 2017, 06/Vol 87/2017.

Bronstein, M. M. et al. (2017). Geometric deep learning: going beyond euclidean data. IEEE Signal Processing Magazine, 34(4), pp. 18-42. 